\title{
Mortality profile across our Intensive Care Units: A 5-year database report from a Singapore restructured hospital
}

\author{
Shahla Siddiqui
}

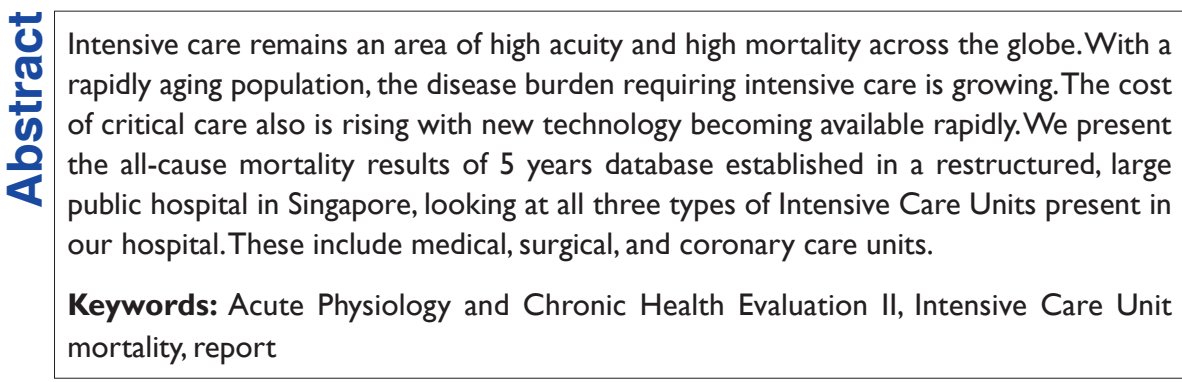

\section{Introduction}

Traditionally, the modern Intensive Care Unit (ICU) has the highest mortality compared to any other sections of a hospital. ${ }^{[1]}$ The ICU mortality trends across Singapore are so far unreported. The average ICU mortality rate reported in the US ranges from $8 \%$ to $19 \%$, or about 500,000 deaths annually. ${ }^{[2]}$ The ICU serves a patient population, which is extremely ill and undergoes multiple complex interventions. In addition to its impact on mortality, critical care is a costly component of the hospital budget. These costs are largely explained by the length of stay and interventions in the ICU. ${ }^{[3]}$ For these reasons, there has been substantial interest in measuring ICU outcomes, both in terms of mortality and resource utilization across the globe. Singapore has seven restructured hospitals with on average two ICUs in each hospital. A national database registry is planned for the coming years to measure ICU outcomes across all units. As a prelude to this data, we present

\section{From:}

Department of Anaesthesia, Khoo Teck Puat Hospital, 90 Yishun Central, Singapore 768828

\section{Correspondence:}

Dr. Shahla Siddiqui, Department of Anaesthesia, Khoo Teck Puat Hospital, 90 Yishun Central, Singapore 768828.

E-mail: shahlas@yahoo.com

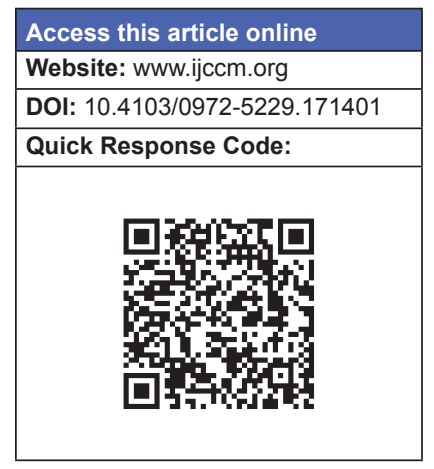

5 years report on data collected from an automated ICU database established at one such hospital in Singapore. Given the scarcity of ICU beds in general and the cost of delivering care in such highly specialized units, it becomes imperative to be familiar with such data. ${ }^{[4]}$ An added burden is the rapidly aging population globally and particularly in Asia. ${ }^{[5]}$ With life expectancy in the $80 \mathrm{~s}$ and more demands on critical care resources by such individuals, outcomes data becomes essential. ${ }^{[6]}$

\section{Methods}

In our 500 bedded hospital, ICU and High Dependency Unit (HDU) beds are housed in one section and comprise $8 \%$ of total beds. HDU beds are for step down care. We have medical, surgical, and cardiac ICUs (MICU, SICU, CCU) with the most beds in MICU and least in CCU.

This is an open access article distributed under the terms of the Creative Commons Attribution-NonCommercial-ShareAlike 3.0 License, which allows others to remix, tweak, and build upon the work non-commercially, as long as the author is credited and the new creations are licensed under the identical terms.

For reprints contact: reprints@medknow.com

How to cite this article: Siddiqui S. Mortality profile across our Intensive Care Units: A 5-year database report from a Singapore restructured hospital. Indian J Crit Care Med 2015;19:726-7. 
We have established an Institutional Review Board approved automated database in our hospital, which collects ICU outcomes data electronically. Our report is a result of inquiring into this database retrospectively for analysis. Data collected includes admission specific data, diagnostic criteria, outcomes, and therapeutic interventions. Data were collected from July 2010 to March 2015. We have analyzed the data collectively as well as specific to each unit (MICU, SICU and CCU).

\section{Results}

We have included 14,500 admissions in total over the specified time period in three ICUs. On an average, there are 1080, 1200, and 600 admissions in MICU, SICU, and $\mathrm{CCU}$, respectively per year. Of these, there were 1134 mortalities, which make up 7\% overall mortality. Individual average mortality was $7 \%$ in MICU, $8.5 \%$ in SICU, and $8.2 \%$ in CCU. Of the mortalities, the male to female ratio across the ICUs was roughly 60:40. The average age group was 60-69 years in MICU and SICU, but 70-79 years in CCU over 5 years. The patients who were $>90$ years and died in our ICUs in this time period was $3 \%$ and those over 80 years made up a quarter of all deaths. Average admission of $>90 \%$ year old patients was $10 \%$. More than $85 \%$ of all deaths occurred in ventilated patients. Average Acute Physiology and Chronic Health Evaluation II score was 20.

Septic shock was the primary diagnosis in MICU patients while septic shock, and neurological events were the major cause of mortality in SICU patients, such as severe head injury or brain death from a cerebral edema caused by the acute bleed. Acute myocardial injury and sepsis caused most of the CCU deaths. The rate of tracheostomy carried out was $8 \%$ in SICU and $4 \%$ and $1.5 \%$, respectively in MICU and CCU. The rates of dialysis in deceased patients were highest in MICU patients (20\%) while SICU and CCU both had a $14 \%$ rate of dialysis in patients who died. Nine-two percentage of mortalities were on vasopressors in the CCU while $84 \%$ of MICU, and $76 \%$ of SICU mortalities on average received vasopressors at the time of death. Ventilator-associated pneumonia (Vap) rates are $4 \%$, $4 \%$ and $6 \%$ in SICU, MICU, and CCU, respectively. However, mortality from VAP was $<5 \%$.

\section{Discussion}

Establishing databases and studying outcome trends adds to key knowledge about performance and resource allocation. Important information about the mortality of ICU patients among different ICUs can also guide in decisions regarding the burden of treatment and success rates. ${ }^{[7]}$ Comparison within the country and with international units can be done resulting in quality improvement. This study shows a limited amount of data across all ICUs, which although is retrospective but includes a large cohort. A worrying trend is the number of elderly patients admitted across all ICUs (above 80 years), mostly requiring aggressive life-sustaining care. Whether triage decisions and end of life decision making can be changed on the basis of such data remains to be seen, and will certainly require more detailed studies. Focus on database derived outcomes research has been achieved in many countries where high cost-benefits models exist. The ICU bears roughly $20 \%$ of any hospital budget and deserves a close look at its performance and goal achievements..$^{[8]}$ Our all-cause ICU mortality rate across the board over 5 years is within international standards. However, it would be interesting to further compare these trends with other hospitals in the country.

\section{Limitations}

While the data are from a single teaching hospital, the rates could be improved as such by investigating the possible factors affecting the outcomes such as nursing staff shortages, training differences, etc. We hope that this report can highlight the importance of comprehensive data in the ICU and more information can be added in subsequent years on a larger scale.

\section{Financial support and sponsorship Nil.}

\section{Conflicts of interest}

There are no conflicts of interest.

\section{References}

1. Molina JA, Seow E, Heng BH, Chong WF, Ho B. Outcomes of direct and indirect Medical Intensive Care Unit admissions from the emergency department of an acute care hospital: A retrospective cohort study. BMJ Open 2014;4:e005553.

2. Mukhopadhyay A, Tai BC, See KC, Ng WY, Lim TK, Onsiong S, et al. Risk factors for hospital and long-term mortality of critically ill elderly patients admitted to an Intensive Care Unit. Biomed Res Int 2014;2014:960575.

3. Angus DC, Linde-Zwirble WT, Sirio CA, Rotondi AJ, Chelluri L, Newbold RC $3^{\text {rd }}$, et al. The effect of managed care on ICU length of stay: Implications for medicare. JAMA 1996;276:1075-82.

4. Halpern NA, Pastores SM. Critical care medicine in the United States 2000-2005: An analysis of bed numbers, occupancy rates, payer mix, and costs. Crit Care Med 2010;38:65-71.

5. Wu AW, Pronovost P, Morlock L. ICU incident reporting systems. J Crit Care 2002;17:86-94.

6. Population Trend 2012. Department of Statistics, Singapore; 2012.

7. Ghassemi M, Celi LA, Stone DJ. State of the art review: The data revolution in critical care. Crit Care 2015;19:118.

8. Celi LA, Csete M, Stone D. Optimal data systems: The future of clinical predictions and decision support. Curr Opin Crit Care 2014;20:573-80. 